\title{
Panel: Method Engineering: Experiences in Practice
}

\author{
Panel Chair:
}

Gezinus J. Hidding, Andersen Consulting, USA

Panelists:

James J. Odell, James Odell Associates, USA

John Parkinson, Ernst \& Young, USA

Gerard M. Wijers, ID Research, the Netherlands

\section{PANEL DESCRIPTION}

Method Engineering is a topic of much research activity witness, for example, this conference. Much of the research focuses on contrasting and comparing various approaches, on repository design, or on design of Computer Aided Method Engineering (CAME) tools. Very little of the research focuses on whether methods are used or useful, let alone whether method engineering is used or valuable.

Some research, for example, by the Software Engineering Institute, suggests that much systems development work is being done without any formalized procedures for doing or managing the work (Masters and Kitson, 1992). Other researchers, e.g., Orr (1993), even argue that methodologies are not very useful. Ciborra (1993) argues that the a-conflictual and mechanistic nature of structured system development approaches does not even fit the current, and complex reality.

However, as Wynekoop and Russo (1993) argued, empirical results or research into experiences with methods (engineering) in practice are rare. Are practitioners using methods, let alone method engineering? Are there different practitioner segments, with different information needs? What are their experiences? What does it even mean to "use" methods? Research by the panel chair indicates that practitioners who use methods do so subconsciously. Their work reveals the method(s) they apply, but they don't read those methods actively anymore. How does methods use or non-use impact an organization's operations? How does it impact an organization's business results (e.g., better quality, faster turn around time, less cost, more productive)? Clearly, such questions are important, as investments in the development and training in such methods are substantial. The panelists, all close to practical applications of Method Engineering, will address these types of questions in their position statements.

\section{REFERENCES}

Ciborra, C., Teams, Markets and Systems: Business Innovation and Information Technology. Cambridge, Great Britain: Cambridge University Press, 1993. 
Masters, S., and Kitson, D.H., An Analysis of SEI Software Process Assessment Results: 1987 - 1991. Technical Report CMU/SEI-92-TR-24. Software Engineering Institute, Carnegie Mellon University. Pittsburgh, PA. 1992.

Orr, J.E., Ethnography and Organizational Learning: In Pursuit of Learning at Work. In: Organizational Learning and Technological Change. Eds. Bagnara, S., C. Zucchermaglio and S. Stucky, New York and Berlin: Springer-Verlag, 1993.

Wynekoop, J.L., and Russo, N.L., System Development Methodologies: Unanswered Questions and the Research-Practice Gap. Proceedings of the Fourteenth International Conference on Information Systems. Orlando. Eds. J.I. DeGross, R.P. Bostrom and D. Robey, pp. 181 - 190, 1993. 